\title{
Lethal Multiple Pterygium Syndrome
}

National Cancer Institute

\section{Source}

National Cancer Institute. Lethal Multiple Pterygium Syndrome. NCI Thesaurus. Code C101038.

A rare variant of multiple pteryg ium syndrome, characterized by severe athrogryposis, pterygium, akinesia and often hydrops fetalis and cystic hygroma. This variant is fatal, usually during the second or third trimester of pregnancy. 